\title{
Chronic Unpredictable Stress Exacerbates Lipopolysaccharide-Induced Activation of Nuclear Factor- $\kappa B$ in the Frontal Cortex and Hippocampus via Glucocorticoid Secretion
}

\author{
Carolina Demarchi Munhoz, ${ }^{1}$ Lucilia B. Lepsch, ${ }^{1}$ Elisa Mitiko Kawamoto, ${ }^{1}$ Marília Brinati Malta, ${ }^{1}$ Larissa de Sá Lima, ${ }^{1}$ \\ Maria Christina Werneck Avellar, ${ }^{2}$ Robert M. Sapolsky, ${ }^{3}$ and Cristoforo Scavone ${ }^{1}$ \\ ${ }^{1}$ Department of Pharmacology, Institute of Biomedical Science, University of São Paulo, São Paulo, Brazil 05508-900, ${ }^{2}$ Section of Experimental \\ Endocrinology, Department of Pharmacology, Federal University of São Paulo-Escola Paulista de Medicina, São Paulo, Brazil 04044-020, and ${ }^{3}$ Department \\ of Biological Sciences, Stanford University, Stanford, California 94305-5020
}

\begin{abstract}
Although the anti-inflammatory actions of glucocorticoids (GCs) are well established in the periphery, these stress hormones can increase inflammation under some circumstances in the brain. The transcription factor nuclear factor $-\kappa \mathrm{B}(\mathrm{NF}-\kappa \mathrm{B})$, which is inhibited by GCs, regulates numerous genes central to inflammation. In this study, the effects of stress, GCs, and NMDA receptors on lipopolysaccharide (LPS)-induced activation of NF- $\kappa$ B in the brain were investigated. One day after chronic unpredictable stress (CUS), nonstressed and CUS rats were treated with saline or LPS and killed $2 \mathrm{~h}$ later. CUS potentiated the increase in LPS-induced activation of NF- $\kappa$ B in frontal cortex and hippocampus but not in the hypothalamus. This stress effect was blocked by pretreatment of rats with RU-486, an antagonist of the GC receptor. MK-801 [(+)-5-methyl-10,11-dihydro-5H-dibenzo [a,d] cyclohepten-5,10-imine maleate], an NMDA receptor antagonist, also reduced the effect of LPS in all three brain regions. However, the combined antagonism of both GC and NMDA receptors produced no further reduction in NF- $\kappa \mathrm{B}$ activation when compared with the effect of each treatment alone. Our results indicate that stress, via GC secretion, can increase LPS-induced NF- $\kappa \mathrm{B}$ activation in the frontal cortex and hippocampus, agreeing with a growing literature demonstrating proinflammatory effects of GCs.
\end{abstract}

Key words: glucocorticoids; chronic stress; NF- $\kappa \mathrm{B}$; LPS; NMDA; brain

\section{Introduction}

Glucocorticoids (GCs), secreted by the adrenals during stress, have long been known to be anti-inflammatory and immunosuppressive; these actions are the rationale behind their frequent clinical use. The anti-inflammatory actions of GCs involve nuclear factor $-\kappa \mathrm{B}(\mathrm{NF}-\kappa \mathrm{B})$ (De Bosscher et al., 2000; Almawi and Melemedjian, 2002). This transcription factor is constitutively expressed in the cytoplasm and is inhibited by inhibitor $\kappa \mathrm{B}(\mathrm{I} \kappa \mathrm{B})$, which binds NF- $\kappa \mathrm{B}$, masking its nuclear localization signal and retaining it in the cytoplasm (Ghosh et al., 1998). NF- $\kappa$ B activity is attributed to Rel/NF- $\kappa \mathrm{B}$ family proteins forming homodimers and heterodimers through the combination of the subunits p65

Received Sept. 10, 2004; revised Feb. 7, 2006; accepted Feb. 8, 2006.

This work was supported by research grants to C.S. from Fundação de Amparo à Pesquia do Estado de São Paulo (FAPESP) (2002/02298-2 and 2004/11041-0) and Fundo Bunka de Pesquisa-Banco Sumitomo. C.D.M. was supported by FAPESP (01/12590-0 and 04/11042-7) and Conselho Nacional de Desenvolvimento Científico e Tecnológico (CNPq) (201059/2003-7). L.B.L. and E.M.K. are student fellows supported by FAPESP. L.d.S.L. was supported by the University of São Paulo. C.S. and M.C.W.A. are research fellows from CNPq. R.M.S. was supported by National Institutes of Health Grants R01 MH53814 and P01 NS37520. We thank Maria Aparecida Fernadez for technical assistance.

Correspondence should be addressed to Cristoforo Scavone, Department of Pharmacology, Institute of Biomedical Science-ICB-1, Avenida Professor Lineu Prestes, 1524, University of São Paulo, São Paulo, Brazil 05508-900. E-mail: cscavone@icb.usp.br.

DOl:10.1523/JNEUROSCI.4398-05.2006

Copyright $\odot 2006$ Society for Neuroscience $\quad$ 0270-6474/06/263813-08\$15.00/0 (or RelA), p50, p52, c-Rel, or RelB. Lipopolysaccharide (LPS), interleuken $1 \beta$ (IL-1 $\beta$ ), tumor necrosis factor- $\alpha$ (TNF- $\alpha$ ), and reactive oxygen species all induce NF- $\kappa \mathrm{B}$ by activating $\mathrm{I} \kappa \mathrm{B}$ kinases. These phosphorylate $\mathrm{I} \kappa \mathrm{B} \alpha$, leading to its polyubiquitination and degradation (Ghosh and Karin, 2002), allowing NF- $\kappa$ B to migrate to the nucleus, where it activates the transcription of various proinflammatory genes. GCs induce $\mathrm{I} \kappa \mathrm{B} \alpha$ expression, preventing nuclear translocation of NF- $\kappa \mathrm{B}$ (Aljada et al., 1999; Quan et al., 2000), and interact with the NF- $\kappa$ B p65 subunit, thereby blocking NF- $\kappa$ B-binding activity (Unlap and Jope, 1997; De Bosscher et al., 2000; McKay and Cidlowski, 2000).

The clinical use of GCs for their anti-inflammatory actions extends to the nervous system; there, they are often used, for example, to counter the edema associated with stroke or brain tumor. As such, one would expect GCs, as well as stress, to inhibit $\mathrm{NF}-\kappa \mathrm{B}$ signaling in the injured nervous system, as elsewhere. The purpose of this study was to examine the effects of chronic unpredictable stress on LPS-induced activation of NF- $\kappa \mathrm{B}$ in a number of brain regions. This was done with the expectation that the predicted inhibition of NF- $\kappa \mathrm{B}$ would be found. However, contrary to this prediction, we observed stress to potentiate NF- $\kappa$ B signaling.

\section{Materials and Methods}

Chemicals and kits. LPS (from Escherichia coli O111:B4) and RU-486 were purchased from Sigma (St. Louis, MO), dizolcipine [(+)-5-methyl- 
10,11-dihydro-5H-dibenzo [a,d] cyclohepten-5,10-imine maleate (MK801)] maleate was obtained from Research Biochemicals International (Natick, MA), $\gamma^{-32}$ P-ATP and poly dI-dC were obtained from Amersham Biosciences (Uppsala, Sweden), the gel shift assay system kit for NF- $\kappa \mathrm{B}$ was obtained from Promega (Madison, WI), and the protein assay kit was obtained from Bio-Rad (Hercules, CA).

Unpredictable stress paradigm. Adult male Wistar rats (300-350 g; Biomedical Sciences Institute, University of São Paulo) were kept under a $12 \mathrm{~h} \mathrm{light/dark} \mathrm{cycle} \mathrm{(lights} \mathrm{on} \mathrm{at} \mathrm{7:00} \mathrm{A.M.)} \mathrm{and} \mathrm{fed} \mathrm{ad} \mathrm{libitum.} \mathrm{Rats} \mathrm{were}$ randomly assigned to either the control (nonstressed) or chronic unpredictable stress (CUS) group. CUS was modified from (Ortiz et al., 1996) and applied as follows: day 1 (2:00 P.M.) restraint, $60 \mathrm{~min}$; day 2 (9:00 A.M.) forced swim, $15 \mathrm{~min}$; day 3 (3:00 P.M.) cold isolation, $90 \mathrm{~min}$; day 4 (7:00 P.M.) lights on, overnight; day 5 (10:00 A.M.) forced swim, 5 min; day 6 (7:00 P.M.) water and food deprivation, overnight; day 7 (2:00 P.M.) restraint, $120 \mathrm{~min}$; day 8 (3:00 P.M.) lights off, $120 \mathrm{~min}$; day 9 (9:00 A.M.) forced swim, $5 \mathrm{~min}$; day 10 (7:00 P.M.) lights on, overnight; day 11 (2:00 P.M.) cold isolation, $90 \mathrm{~min}$; day 12 (9:00 A.M.) restraint, 60 min; day 13 (7:00 P.M.) water and food deprivation, overnight; and day 14 (9:00 A.M.) restraint, $60 \mathrm{~min}$. In all stress experiments, the CUS rats were exposed to the same order of stressful stimuli. This model was selected because previous studies (Cullinan et al., 1995; Herman et al., 1995; Cullinan and Wolfe, 2000) have shown that CUS results in hallmark signs of chronic overexposure to GCs, such as increased adrenal weight, reduced thymus weight, reduced body weight gain, and increased plasma corticosterone levels. Furthermore, the mixture of psychological and physical stressor found in the CUS paradigm not only reduces the chances of adaptation but also better mimics the variability of stressors encountered in daily life (Joels et al., 2004). All animals were studied $1 \mathrm{~d}$ after the last stressor. The control rats were manipulated every day for 10 $\mathrm{min}$ in the home cage to control for nonspecific handling effects.

Injections. Twenty four hours after the last stress session, control and CUS groups were treated with either LPS dissolved in sterile saline (1 $\mathrm{mg} / \mathrm{kg}$, i.v. bolus) or sterile saline and killed by decapitation $2 \mathrm{~h}$ later, when maximal NF- $\kappa \mathrm{B}$ binding activation is obtained in different brain regions (Glezer et al., 2003). The brain was removed and immersed in cold PBS. The frontal cortex, hypothalamus, and hippocampus were rapidly dissected, quickly immersed in liquid nitrogen, and stored at $-80^{\circ} \mathrm{C}$ for later use.

For the assessment of the effects of MK-801 (1 mg/kg, dissolved in saline) and RU-486 (50 mg/kg/200 $\mu$ l, dissolved in DMSO), rats were treated with intraperitoneal injection of the drug or vehicle alone $30 \mathrm{~min}$ before LPS treatment. Doses were based on a previous study (Sheridan et al., 1998).

All animal treatments were performed between 9:00 and 11:00 A.M. All experiments were in accord with the ethical principles in animal research adopted by the Biomedical College of Animal Experimentation and approved by the Ethical Committee for Animal Research of the Biomedical Sciences Institute, University of São Paulo.

Electrophoretic mobility shift assay to NF- $\kappa B$ consensus oligonucleotide. Nuclear extracts of each brain structure were prepared as described previously (Rong and Baudry, 1996). Briefly, brain structures were homogenized in cold PBS (complemented with $0.1 \mathrm{~mm}$ EDTA, $0.5 \mathrm{~mm}$ DTT, 0.5 mM PMSF) using a Dounce homogenizer and centrifuged at $4^{\circ} \mathrm{C}$ for $30 \mathrm{~s}$ at $12,000 \times g$. The supernatants $(\mathrm{S} 1)$ were kept on ice, and the pellets were resuspended in lysis buffer (10 mM HEPES, pH 7.9, $1.5 \mathrm{~mm} \mathrm{MgCl}_{2}$, $10 \mathrm{~mm} \mathrm{KCl}, 0.1 \mathrm{~mm}$ EDTA, $0.5 \mathrm{~mm}$ DTT, $0.5 \mathrm{~mm}$ PMSF) and incubated on ice for $10 \mathrm{~min}$. After addition of $0.25 \% \mathrm{NP}-40$, samples were vigorously mixed and centrifuged for $30 \mathrm{~s}$ at 12,000 $\times$ g. Supernatants (S1 and S2) were mixed and used as citosolic fraction in the Western blot assays, and nuclei were resuspended in extraction buffer (20 mM HEPES, pH 7.9, $25 \%$ glycerol, $1.5 \mathrm{~mm} \mathrm{MgCl}_{2}, 300 \mathrm{~mm} \mathrm{NaCl}, 0.25 \mathrm{~mm}$ EDTA, $0.5 \mathrm{~mm}$ DTT, $0.5 \mathrm{~mm}$ PMSF), incubated for $20 \mathrm{~min}$ on ice, and centrifuged for $20 \mathrm{~min}$ at $12,000 \times g$ at $4^{\circ} \mathrm{C}$. The resulting supernatants containing nuclear proteins were stored at $-80^{\circ} \mathrm{C}$. Protein concentration was determined using the Bio-Rad protein reagent. Nuclear extracts of the rat heart were also prepared, as described previously (Nishio et al., 1998), to be used as positive controls.

Electrophoretic mobility shift assay (EMSA) to NF- $\kappa$ B was performed by using the gel shift assay kit from Promega, as described previously (Rong and Baudry, 1996). ${ }^{32} \mathrm{P}-\mathrm{NF}-\kappa \mathrm{B}$ double-stranded consensus oligonucleotide probe $\left(5^{\prime}\right.$-AGTTGAGGGGACTTTCCCAGGC-3') $(20,000$ $\mathrm{cpm})$ and nuclear extracts $(10-15 \mu \mathrm{g})$ were used. DNA-protein complexes were separated by electrophoresis through a $6 \%$ nondenaturing acrylamide:bis-acrylamide (37.5:1) gel in $0.5 \times$ Tris-borate/EDTA for $2 \mathrm{~h}$ at $150 \mathrm{~V}$. Gels were vacuum dried and analyzed by autoradiography. For competition experiments, NF- $\kappa \mathrm{B}$ and transcription iniciation factor IID (TFIID) (5'-GCAGAGCATATAAGGTGAGGTAGGA-3') unlabeled double-stranded consensus oligonucleotide was included in 10- and 20fold molar excess over the amount of ${ }^{32} \mathrm{P}-\mathrm{NF}-\kappa \mathrm{B}$ probe to detect specific and nonspecific DNA-protein interactions, respectively. Supershift assays, using antibodies against different NF- $\kappa$ B subunits (p50 and p65, 1:20 dilution; p52, 1:10 dilution), were also conducted according to the protocol of the manufacture (Santa Cruz Biotechnology, Santa Cruz, CA). Autoradiographs were quantified by ChemImager detection system (Alpha-Innotech, San Leandro, CA), and several exposure times were analyzed to ensure the linearity of the band intensities.

Western blot of nuclear and cytosolic p $65 \mathrm{NF}-\kappa \mathrm{B}$ subunit. Electrophoresis was performed using $10 \%$ polyacrylamide and the Bio-Rad miniProtean II apparatus. In brief, the proteins present in the cytosolic (20 $\mu \mathrm{g})$ and nuclear fractions $(10 \mu \mathrm{g})$ were size-separated in 10\% SDS-PAGE $(90 \mathrm{~V})$. The proteins were blotted onto a nitrocellulose membrane (BioRad) and incubated with the specific antibody (p65 sc-372; Santa Cruz Biotechnology). To ensure equal protein loading, we used the Ponceau method to Western blot (Salinovich and Montelaro, 1986). Proteins recognized by antibodies were revealed by ECL technique, following the instructions of the manufacturer (Amersham Biosciences). To standardize and quantify the Western blots, we used the ChemImager detection system (Alpha-Innotech). Several exposure times were analyzed to ensure the linearity of the band intensities. $\beta$-Actin antibody (sc-1616; Santa Cruz Biotechnology) was used as an internal control of the experiments.

$I L-1 \beta$, inducible nitric oxide synthase, and TNF- $\alpha$ mRNA expression. The effect of stress on NF- $\kappa \mathrm{B}$-modulated gene expression in the frontal cortex and hippocampus of rats was measured. Total RNA was isolated with Trizol reagent (Invitrogen, Carlsbad, CA) according to the instructions of the manufacturer. Semiquantitative reverse transcription-PCR (RT-PCR) amplification was performed using the ThermoScript RT kit (Invitrogen) according to the instructions of the manufacturer. The primer sequences were as follows: IL-1 $\beta$ (519 bp), 5'-ATG CTC AGC AGT CAA GTG CC-3' (sense) and 5' -AGC CTT CCT TCG TGT AAC CC-3' (antisense); inducible nitric oxide synthase (iNOS) (651 bp), 5' ACA ACA GGA TAC CAG CTC A-3' (sense) and 5'-GAT GTT GTA GCG CTG TGT GTC A-3' (antisense); TNF- $\alpha$ (480 bp), $5^{\prime}$-AGG CGC TCC CCA AAA AGA TG-3' (sense) and 5'-GAT GGC GGA GAG GAG GCT GA-3' (antisense). The PCR cycles consisted of $5 \mathrm{~min}$ at $94^{\circ} \mathrm{C}, 33$ cycles of $94^{\circ} \mathrm{C}$ for $45 \mathrm{~s}, 63^{\circ} \mathrm{C}$ for $45 \mathrm{~s}$, and $72^{\circ} \mathrm{C}$ for $1 \mathrm{~min}$ and $30 \mathrm{~s}$ (IL- $1 \beta$; $519 \mathrm{bp}$ ); 30 cycles of $94^{\circ} \mathrm{C}$ for $45 \mathrm{~s}, 66^{\circ} \mathrm{C}$ for $45 \mathrm{~s}$, and $72^{\circ} \mathrm{C}$ for $1 \mathrm{~min}$ and $30 \mathrm{~s}$ (iNOS; $651 \mathrm{bp}$ ); 37 cycles of $94^{\circ} \mathrm{C}$ for $45 \mathrm{~s}, 59^{\circ} \mathrm{C}$ for $45 \mathrm{~s}$, and $72^{\circ} \mathrm{C}$ for $1 \mathrm{~min}$ and $30 \mathrm{~s}$ (TNF- $\alpha ; 480 \mathrm{bp}$ ) and a final extension at $72^{\circ} \mathrm{C}$ for $10 \mathrm{~min}$. Glyceraldehyde-3-phosphate dehydrogenase (GAPDH; 357 bp) was also amplified as an internal PCR control using the following primers: $5^{\prime}$ GCC AAG TAT GAT GAC ATC AAG AAG-3' (sense) and 5' -TCC AGG GGT TTC TTA CTC CTT GGA-3' (antisense). The temperature cycling conditions were as follows: $5 \mathrm{~min}$ at $94^{\circ} \mathrm{C}, 20$ cycles of $94^{\circ} \mathrm{C}$ for $45 \mathrm{~s}, 63^{\circ} \mathrm{C}$ for $45 \mathrm{~s}$, and $72^{\circ} \mathrm{C}$ for $1 \mathrm{~min}$ and $30 \mathrm{~s}$ and a final extension at $72^{\circ} \mathrm{C}$ for 10 min. Gel electrophoresis of the PCR product was performed using an ethidium bromide-containing agarose gel (2\%), and resulting bands were visualized under UV light. The photographs were scanned (HP 1200 series; Hewlett-Packard, Palo Alto, CA), and the optical density of the bands was quantified using NIH ImageJ software.

Statistical analysis. Results are expressed as mean \pm SEM of the indicated number of experiments. Statistical comparisons were performed in each brain structure individually by two-way ANOVA (stress $X$ injection) followed by Bonferroni's test. Significance for all tests was set at $p<$ 0.05. All analyses were performed with Prim 4 software package (Graphpad Software, San Diego, CA). 

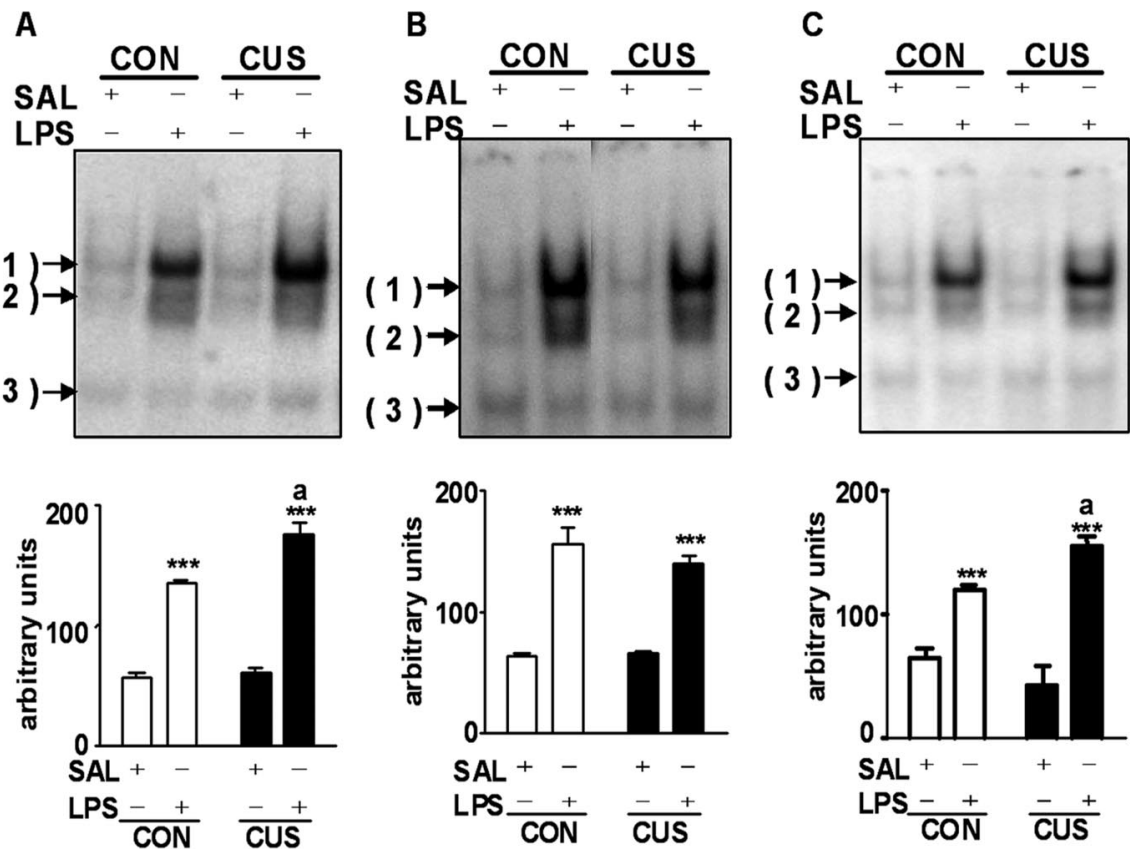

Figure 1. Effect of CUS on NF- $\kappa B$ activation induced by LPS or saline (SAL) in the frontal cortex $(\boldsymbol{A})$, hypothalamus $(\boldsymbol{B})$, or hippocampus (C). Top, Representative EMSA autoradiography. Major specifics (bands 1 and 2) and nonspecific (band 3) DNA interactions are indicated by arrows. Bottom, Densitometric analysis of band 1 (representing p65/p50 heterodimers) presented in the top panel [mean $\pm \mathrm{SEM} ; n=5$ animals per group; Bonferroni's test, ${ }^{* * *} p<0.001$ vs SAL; ${ }^{a} p<0.05$ vs control (CON) plus LPS].

\section{Results}

\section{Effects of CUS on LPS-induced activation of NF- $\kappa$ B}

binding activity

Confirming our previous results (Glezer et al., 2003), LPS activated NF- $\kappa \mathrm{B}$ binding activity within $2 \mathrm{~h}$ in the frontal cortex, hypothalamus, and hippocampus [ANOVA, LPS (Fig. 1a), $F_{(1,16)}=329.99, p<0.005$; (Fig. $\left.1 b\right) F_{(1,16)}=99.36, p<0.0001$; (Fig. 1c) $\left.F_{(1,16)}=222.16, p<0.0001\right]$.

Fourteen days of CUS, in the absence of LPS, did not alter NF- $\kappa \mathrm{B}$ binding activity. However, stress augmented the effects of LPS on NF- $\kappa \mathrm{B}$ binding activity in the frontal cortex (Fig. 1a) $\left(\right.$ ANOVA, stress, $F_{(1,16)}=18.94, p=0.0005$; stress $\times$ LPS, $\left.F_{(1,16)}=11.90, p<0.005\right)$ and the hippocampus (Fig. 1c) $\left(F_{(1,16)}=29.96, p<0.0001\right.$; stress $\times$ LPS, $\left.F_{(1,16)}=3.63, p>0.05\right)$ but not the hypothalamus (Fig. $1 b)\left(F_{(1,16)}=0.75 ; p>0.05\right.$, NS).
Nuclear extracts analyzed from all three brain regions produced a similar pattern of three DNA/protein complexes (Fig. 2). The upper complexes 1 and 2 were displaced by an excess of unlabeled NF- $\kappa \mathrm{B}$, but not by TFIID double-stranded oligonucleotide consensus sequence, demonstrating the specificity of $\mathrm{NF}-\kappa \mathrm{B} / \mathrm{DNA}$ binding interaction. The lower complex 3 was less efficiently displaced by unlabeled NF- $\kappa \mathrm{B}$, representing a nonspecific binding.

Supershift analysis in control and CUS rats indicated that the antibody against the NF- $\kappa \mathrm{B}$ p65 subunit shifted DNA/protein interactions present in complex 1 . The antibody against the p50 subunit shifted complex 2 and partially decreased complex 1 . In contrast, the antibody against the p52 subunit did not affect DNA-protein complexes (Fig. 2). Together, these results indicate that p65/p50 heterodimers and p50/p50 homodimers are present in ${ }^{32} \mathrm{P}$ $\mathrm{NF}-\kappa \mathrm{B} /$ protein complexes 1 and 2 , respectively. Complex 3 was not affected significantly by the presence of antibodies against the different NF-kB subunits. Because complex 1, mainly composed by p65/p50 heterodimers, was the major DNA/protein complex altered by the treatments, the term NF- $\kappa \mathrm{B}$ was used to discriminate this complex.

Involvement of GCs in the effects of stress after LPS-induced $\mathrm{NF}-\kappa \mathrm{B}$ binding activity

Because GC levels were elevated $24 \mathrm{~h}$ after the last stress session (data not shown), we tested whether this sustained GC increase helped mediate the effects of stress on LPS-induced NF- $\kappa$ B binding activity.

Administration of RU-486 (50 mg/kg), a GC receptor antagonist, 30 min pre-LPS blunted the potentiating effects of stress on $\mathrm{NF}-\kappa \mathrm{B}$ binding activity in the frontal cortex (Fig. $3 a$ ) (ANOVA stress, $F_{(1,12)}=15.38, p<0.01$; stress $\times$ treatment, $F_{(1,12)}=$ 36.33, $p<0.001$ ) and hippocampus (Fig. 3c) (stress, $F_{(1,16)}=$ 25.70, $p<0.001$; stress $\times$ treatment, $\left.F_{(1,12)}=24.91, p<0.001\right)$.
A) Frontal Cortex
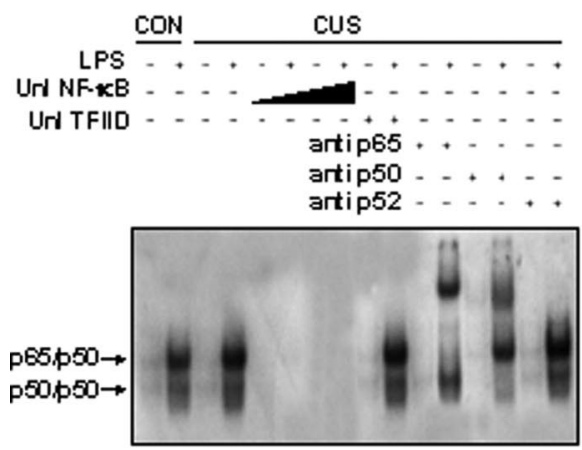

\section{B) Hypothala mus}

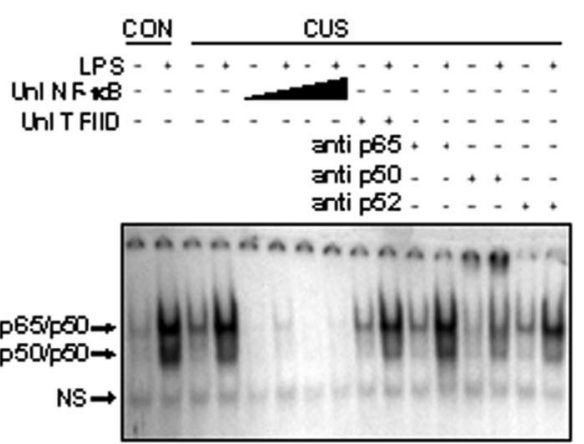

c) Hippocampus

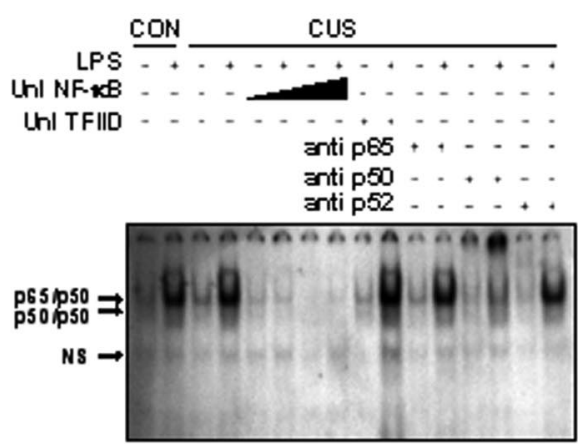

Figure 2. Competition studies and supershift assays were performed on nuclear extract from the frontal cortex $(\boldsymbol{A})$, hypothalamus (B), or hippocampus ( $(\boldsymbol{)}$ of stressed rats (CUS) treated with saline or LPS (1 mg/kg, i.v.; $2 \mathrm{~h}$ ) $+/$ - unlabeled specific (NF- $\kappa$ B consensus sequence, 5 -fold and 10-fold molar excess represented by ) or nonspecific oligonucleotide (TFIIID consensus sequence, 10-fold molar excess), as indicated. Supershift assays were performed with the same nuclear extract incubated $+/-$ antibodies against subunits p50, p65, and p52 (1:10) as indicated. The position of specific NF- $\kappa \mathrm{B} / \mathrm{DNA}$ binding complexes p65/p50 and p50/p50 is indicated. NS, No specific binding ( $n=3$ animals per group). CON, Control. 
In contrast, RU-486 enhanced the effects of LPS on NF- $\kappa \mathrm{B}$ in the hypothalamus of CUS rats (Fig. $3 b$ ) and in all three regions in control rats. In control and CUS rats treated with saline rather than LPS, RU486 had no effect on NF- $\kappa$ B binding activity and did not alter the pattern of ${ }^{32} \mathrm{P}-\mathrm{NF}-$ $\kappa \mathrm{B} /$ protein complexes.

To provide additional evidence of $\mathrm{NF}-\kappa \mathrm{B}$ activation, the translocation to the nucleus of the $\mathrm{p} 65 \mathrm{NF}-\kappa \mathrm{B}$ subunit was addressed by Western blot analysis. LPS caused translocation of this subunit to the nucleus in frontal cortex and hippocampus (frontal cortex, $F_{(2,18)}=12.65, p<$ 0.001 ; hippocampus, $F_{(2,18)}=15.38, p<$ 0.001 ), an effect potentiated by stress (frontal cortex, stress, $F_{(1,18)}=0.03, p>$ 0.05 ; stress $\times$ LPS, $F_{(2,18)}=6.81, p<0.05$; hippocampus, stress, $F_{(1,18)}=0.37, p>$ 0.05 ; stress $\times$ LPS, $\left.F_{(2,18)}=5.34, p<0.05\right)$ (Fig. 4). RU-486 decreased this stress effect in frontal cortex and, to a lesser extent, in the hippocampus.

\section{Involvement of the NMDA receptor in}

the effects of stress after LPS-induced NF- $\kappa \mathrm{B}$ binding activity Because glutamate, via NMDA receptor activation, is associated with both the deleterious effects of stress and GCs (Armanini et al., 1990) and with the effects of LPS on NF- $\kappa$ B binding activity (Guerrini et al., 1995; Kaltschmidt et al., 1995; Glezer et al., 2003), we tested whether NMDA receptors helped mediate the effects of stress after LPS-induced NF- $\kappa$ B binding activity.

Administration of the NMDA receptor antagonist MK-801 (1 $\mathrm{mg} / \mathrm{kg}$ ) blunted LPS-induced NF- $\kappa \mathrm{B}$ binding activity $\sim 20 \%$ in all three regions in both stressed and unstressed rats [ANOVA, frontal cortex (Fig. 5a), stress, $F_{(1,20)}=67.61, p<0.0001$, stress $\times$ treatment, $F_{(1,20)}=3.44, p=0.078$; hypothalamus (Fig. $5 b$ ), stress, $F_{(1,20)}=0.66, p>0.05$, stress $\times$ treatment, $F_{(1,20)}=0.29$, $p>0.05$; hippocampus (Fig. $5 c$ ), stress, $F_{(1,20)}=5.798, p<0.01$, stress $\times$ treatment, $F_{(1,20)}=3.32, p>0.05$, treatment (Fig. $5 a$ ), $F_{(1,20)}=32.64, p<0.001$; (Fig. $\left.5 b\right) F_{(1,20)}=29.65, p<0.001$; (Fig. 5c) $\left.F_{(1,20)}=109.7, p<0.001\right]$. These results replicate reports of a role for NMDA receptors in LPS-induced NF- $\kappa \mathrm{B}$ binding activity in the CNS (Glezer et al., 2003) and also suggest that NMDA receptors have no role in the potentiating effects of stress after LPS-induced binding activity.

MK-801 did not alter NF- $\kappa$ B binding activity or the pattern of ${ }^{32} \mathrm{P}-\mathrm{NF}-\kappa \mathrm{B} /$ protein complexes in stressed or unstressed rats treated with saline, rather than LPS.

\section{Effects of blockade of both GC and NMDA receptors in the LPS-induced NF- $\kappa \mathrm{B}$ binding activity in CUS rats}

To confirm whether GC and NMDA receptors augment NF- $\kappa \mathrm{B}$ activity via the same pathway, we combined the two treatments. RU-486 alone or in combination with MK-801 did not differ in its effects after LPS-induced NF- $\kappa \mathrm{B}$ activity in the frontal cortex and hippocampus of stressed rats. In all three regions of unstressed rats, the combined treatment blunted the LPS-induced NF- $\kappa \mathrm{B}$ activity to nearly the same extent as did MK-801 alone (Fig. 6).
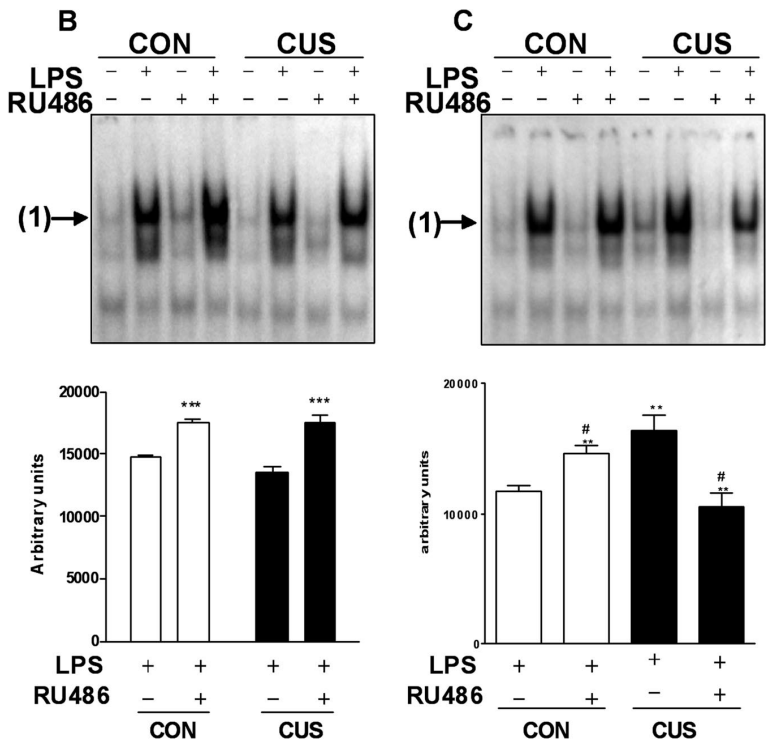

Figure 3. Influence of RU-486 on NF- $\kappa$ B activation induced by LPS in the frontal cortex $(\boldsymbol{A})$, hypothalamus $(\boldsymbol{B})$, or hippocampus 0.05 vs CON plus LPS; ${ }^{\#} p<0.05$ vs (US plus LPS)

A)

Frontal Cortex


B)

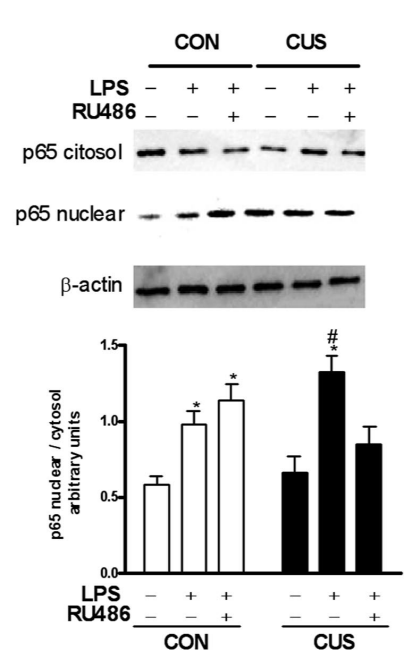

Figure 4. Effect of chronic unpredictable stress (CUS) on p65 subunit NF- $\kappa$ B translocation induced by LPS or saline in the frontal cortex $(\boldsymbol{A})$ and hippocampus $(\boldsymbol{B})$. Top, Representative Western blot autoradiographies. Bottom, Densitometric analysis of p65 nuclear and cytosolic ratio of groups presented in the top panel (mean $\pm S E M ; n=4$ animals per group). Bonferroni's test: ${ }^{*} p<0.05$ versus saline; ${ }^{\#} p<0.05$ versus CON plus LPS. $\beta$-Actin was used as internal control.

Involvement of stress and GC on proinflammatory genes modulated by NF- $\boldsymbol{\kappa} B$

We next examined whether stress also potentiated the effects of LPS after expression of proinflammatory genes known to be induced by NF- $\kappa$ B (i.e., IL- $1 \beta$, iNOS, and TNF- $\alpha$ ). As expected, in unstressed rats, LPS increased expression of these genes in the frontal cortex (Fig. 7) (iNOS, $F_{(2,18)}=23.67, p<0.001$; IL- $1 \beta$, $F_{(2,18)}=19.84, p<0.05$; TNF- $\left.\alpha, F_{(2,18)}=49.59, p<0.0001\right)$ and the hippocampus (iNOS, $F_{(2,18)}=4.49, p<0.05$; IL- $1 \beta, F_{(2,18)}=$ $16.31, p<0.0001$; TNF- $\left.\alpha, F_{(2,18)}=11.81, p<0.001\right)$; further- 



Figure 5. Influence of MK-801 on NF- $\kappa$ B activation induced by LPS in the frontal cortex $(\boldsymbol{A})$, hypothalamus $(\boldsymbol{B})$, or hippocampus (C) of unstressed (CON) or stressed (CUS) rats. Top, Representative EMSA autoradiography. The position of specific NF- $\kappa B / D N A$ binding complex p65/p50 (band 1) is indicated. Bottom, Densitometric analysis of the band 1 (representing p65/p50 heterodimers) of LPS-treated groups presented in the top panel (mean \pm SEM; $n=6$ animals per group). Bonferroni's test: ${ }^{* *} p<$ 0.05 versus CON plus LPS; ${ }^{\#} p<0.05$ versus CUS plus LPS.

A
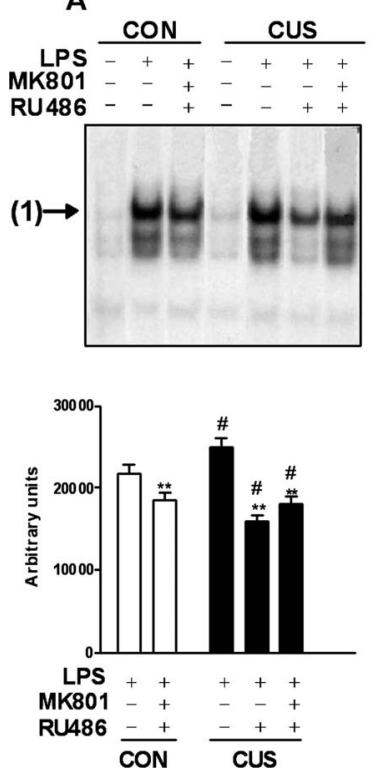

B
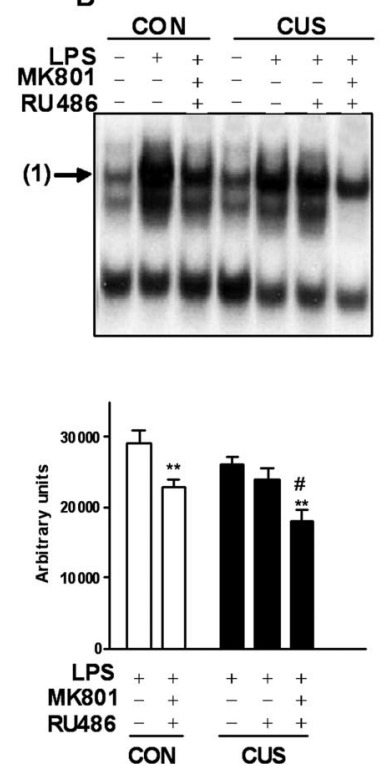

C
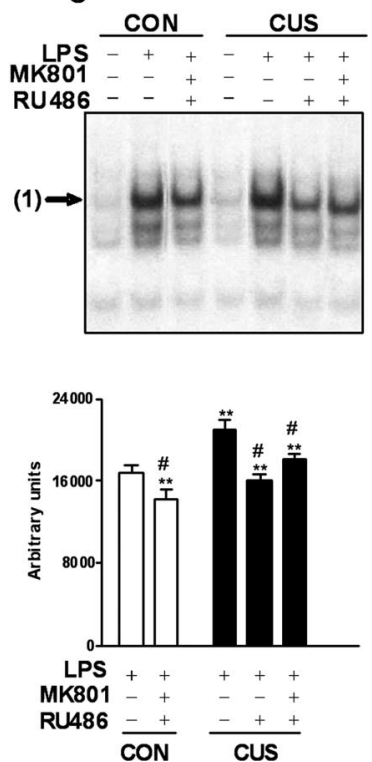

Figure 6. Influence of RU-486 and MK-801 on NF- $\kappa$ B activation induced by LPS in the frontal cortex $(\boldsymbol{A})$, hypothalamus $(\boldsymbol{B})$, or hippocampus ( $C$ ) of unstressed (CON) or stressed (CUS) rats. Top, Representative EMSA autoradiography. The position of specific NF- $\kappa$ B/DNA binding complex p65/p50 (band 1) is indicated. Bottom, Densitometric analysis of the band 1 (representing p65/p50 heterodimers) of LPS-treated groups presented in the top panel (mean $\pm \mathrm{SEM} ; n=5$ animals per group). Bonferroni's test: ${ }^{* *} p<0.05$ versus CON plus LPS; $p<0.05$ versus CUS plus LPS.

more, RU-486 treatment potentiated the LPS effect (Fig. 7). In contrast, stress potentiated the LPS effects; this stress effect was blunted by RU-486 (iNOS: stress, $F_{(1,18)}=0.35, p>0.05$; stress $\times$ LPS, $F_{(2,18)}=9.26, p<0.005$; IL-1 $\beta$ : stress, $F_{(1,18)}=3.49, p>$ 0.05 ; stress $\times$ LPS, $F_{(2,18)}=4,91, p<0.05$; TNF- $\alpha$ : stress, $F_{(1,18)}=2.17, p>0.05$; stress $\times$ LPS, $\left.F_{(2,18)}=19.79, p<0.0001\right)$. Unexpectedly, in the hippocampus, stress only potentiated the effect of LPS-induced gene expression in the case of iNOS (stress, $F_{(1,18)}=4.41, p=0.0501$; stress $\times$ LPS, $\left.F_{(2,18)}=5.48, p<0.05\right)$; stress had no effect on LPS-induced expression of IL- $1 \beta$ and TNF- $\alpha$. However, as seen in the frontal cortex, the treatment with RU-486 significantly blunted the LPS-induced increase in the mRNA levels of all three proinflammatory genes analyzed in the hippocampus of stressed rats (Fig. 7).

\section{Involvement of GCs in the effects of} stress after LPS-induced NF- $\kappa \mathrm{B}$ binding activity in the heart

EMSA was also performed with nuclear extracts from the hearts of unstressed and stressed rats, treated with LPS alone or combined with RU-486, to examine possible GC proinflammatory response outside the nervous system. LPS strongly increased $\mathrm{NF}-\kappa \mathrm{B}$ binding activity in the hearts of unstressed and stressed rats (Fig. 8) $\left(F_{(2,12)}=\right.$ 208.68 ; $p<0.001)$. In contrast to rat frontal cortex and hippocampus, where stress had proinflammatory effects, stress did not affect the LPS-induced NF- $\kappa \mathrm{B}$ binding activity in the heart $\left(F_{(1,12)}=3.73 ; p>\right.$ 0.05). RU-486 increased the effects of LPS on NF- $\kappa \mathrm{B}$ binding activation in both unstressed and stressed animals.

\section{Discussion}

Numerous neurological insults and neurodegenerative disorders induce inflammation. This is characterized by infiltration of blood-borne granulocytes and monocytes/macrophages into brain parenchyma as well as activation of resident microglial cells, astrocyte swelling, and the expression of cytokines such as TNF- $\alpha$, adhesion molecules, and other inflammatory mediators (Floyd, 1999; GonzalezScarano and Baltuch, 1999).

LPS can induce glutamate release in cortical slices (Wang and White, 1999), and proinflammatory compounds such as prostaglandins or TNF- $\alpha$ trigger glutamate release from astrocytes (Bezzi et al., 2001). The activation of proinflammatory transcription factors such as NF- $\kappa \mathrm{B}$ is triggered by the calcium-dependent activation of intracellular second messenger systems, NMDA receptors, reactive oxygen species generation, membrane peroxidation, and deprivation of oxygen and nutrients (Baeuerle and Henkel, 1994; Baldwin, 1996). The activation of this transcription factor modulates the expression of several proinflammatory cytokines that actively participate in the innate immune response (Ghosh et al., 1998; Heese et al., 1998).

As reviewed, the effects of GCs after NF- $\kappa$ B are central to the former's anti-inflammatory effects. As an anti-inflammatory mechanism, GC can increase I $\kappa \mathrm{B}-\alpha$ expression, which binds $\mathrm{NF}-\kappa \mathrm{B}$ in the cytoplasm, preventing its translocation to the nucleus (Quan et al., 2000). In addition, GCs can directly inhibit 
$\mathrm{NF}-\kappa \mathrm{B}$ binding to DNA via interactions between activated GR and the p65-NF- $\kappa \mathrm{B}$ subunit (Unlap and Jope, 1997; McKay and Cidlowski, 2000)

Because GC levels are increased by stress and LPS is a potent inducer of NF- $\kappa \mathrm{B}$ binding activity, we first tested whether chronic stress modulated the effects of LPS on NF- $\kappa$ B activity. Contrary to the picture of stress as anti-inflammatory, CUS augmented the effect of LPS on NF- $\kappa \mathrm{B}$ activation frontal cortex and hippocampus, as well as the effects of LPS on expression of the proinflammatory genes IL- $\beta$, TNF- $\alpha$, and iNOS; this is in agreement with recent reports that stress or GCs can increase levels of proinflammatory cytokine (TNF- $\alpha$, IL- $1 \alpha$, and IL- $1 \beta$ ) in the periphery and brain (Madrigal et al., 2001a; O'Connor et al., 2003). Furthermore, stress not only potentiates LPSinduced expression of IL- $1 \beta$ and TNF- $\alpha$ in the brain but worsens susceptibility to endotoxic shock as well (Quan et al., 2001). We also observed that most of the transcriptional activity altered by LPS administration both in nonstressed and CUS is mediated through the major complex (p50/p65), the same complex reported to respond to LPS or stress (Baeuerle and Henkel, 1994; Madrigal et al., 2001a; Glezer et al., 2003). In the absence of LPS, CUS did not modulate NF- $\kappa \mathrm{B}$ binding activity in any region tested. Whereas an acute stressor increases NF- $\kappa \mathrm{B}$ activity in the frontal cortex of rats and in peripheral blood mononuclear cells of humans (Madrigal et al., 2001a; Bierhaus et al., 2003), the effects of a chronic stressor, as in the present study, have not been examined. The fact that the effects of an acute stressor were not seen after chronic stress suggests a compensatory plasticity that emerges in the latter case.

Because CUS rats had high GC levels at the time of the LPS injection, we tested whether GCs mediate the ability of CUS to potentiate LPS actions. Our results suggest that GCs do so via interaction with GR, because a GC receptor antagonist (RU-486) blunted the potentiating effect of stress on LPS-induced activation of NF-kB in the frontal cortex and hippocampus. These results strongly suggest a proinflammatory role of GCs, in agreement with other recent studies. For example, GCs worsen excitotoxin-induced infiltration of inflammatory cells and expression of proinflammatory cytokines in the hippocampus (Dinkel et al., 2003) or hippocampal culture (Macpherson et al., 2005).

Prolonged stress or exposure to stress levels of GCs can impair the ability of hippocampal and cortical neurons to survive various insults (Stein-Behrens et al., 1992; Krugers et al., 2000; Madrigal et al., 2003) and can augment insult-induced glutamate release and NMDA receptor activation (Armanini et al., 1990; Moghaddam et al., 1994; Madrigal et al., 2001b). Stress itself can

A
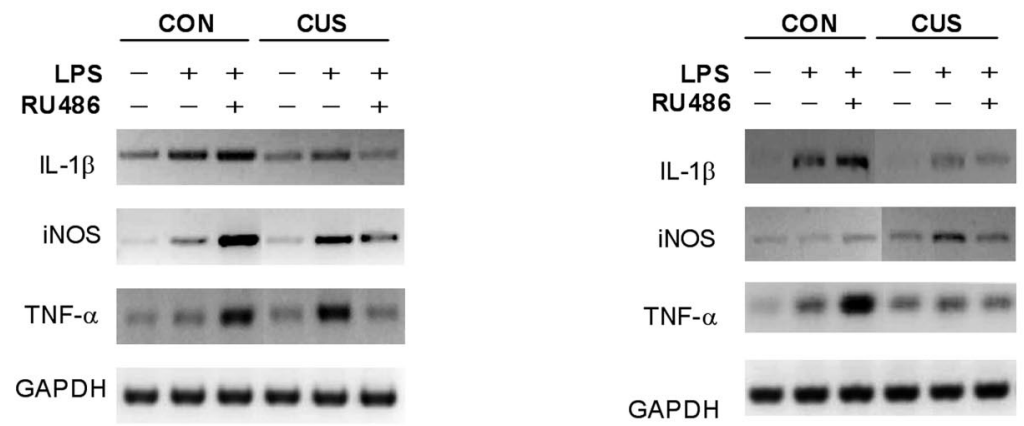

Hippocampus

B Frontal Cortex
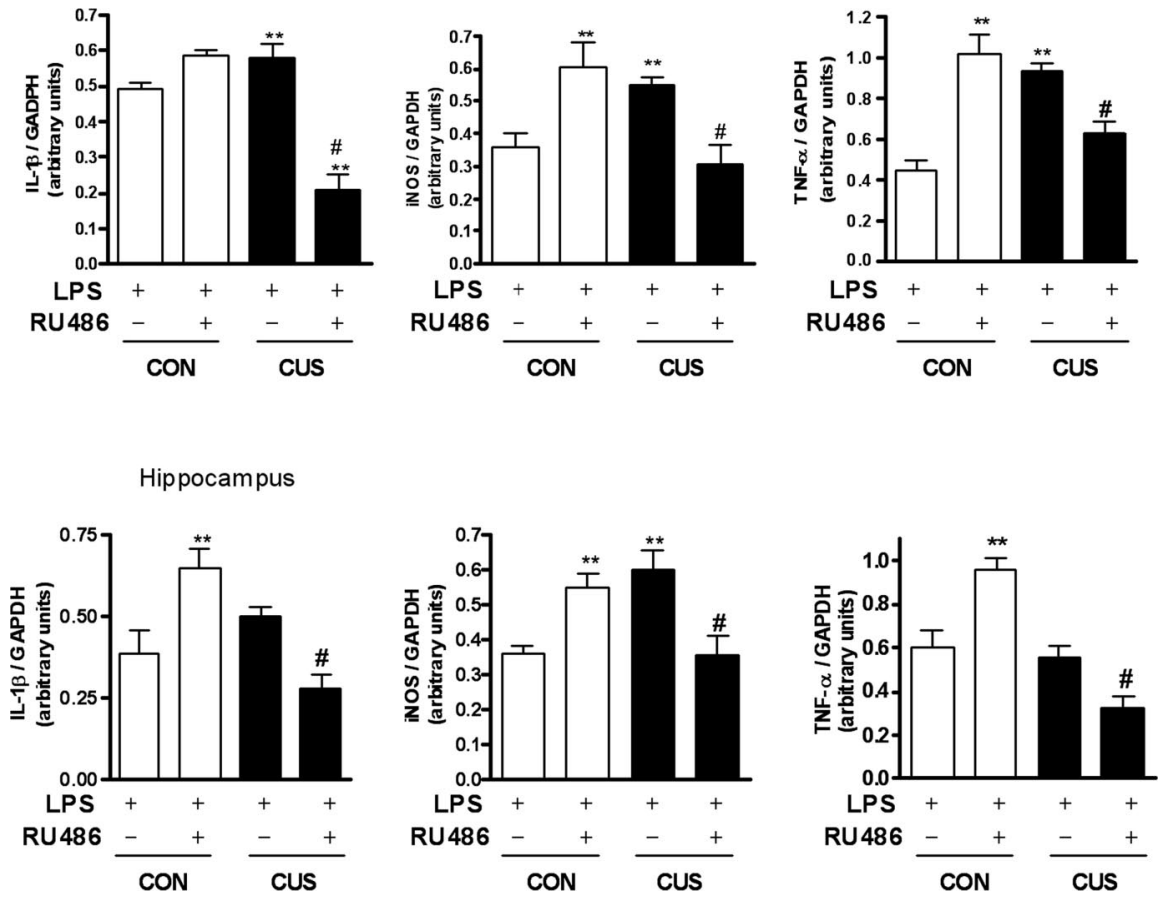

Figure 7. Influence of RU-486 on mRNA levels of proinflammatory genes (IL-1 $\beta$, iNOS, and TNF- $\alpha$ ) induced by LPS in the frontal cortex and hippocampus of unstressed (CON) and stressed (CUS) rats. $\boldsymbol{A}$, Representatives PCR photographies. $\boldsymbol{B}$, Desitometric analysis of the specific bands of LPS-treated groups presented in $\boldsymbol{A}$. mRNA levels is presented as ratios of target gene to GAPDH expression. Data are presented as mean \pm SEM; $n=4$ animals per group. Bonferroni's test: ${ }^{* *} p<0.05$ versus CON plus LPS; ${ }^{\#} p<0.05$ versus CUS plus LPS.

increase glutamate release in both regions and inhibit its uptake by glial transporters (Chou et al., 1994). Glutamate-induced NMDA activation has been shown to induce NF- $\kappa$ B activation in several brain structures (Guerrini et al., 1995; Kaltschmidt et al., 1995; Glezer et al., 2003). Furthermore, acute immobilization stress causes an NMDA receptor-mediated increase in NF- $\kappa \mathrm{B}$ binding activity in the cortex (Madrigal et al., 2001a). Thus, we tested whether glutamate, via the NMDA receptor, could mediate the potentiating effects of stress on LPS-induced NF- $\kappa$ B activation. This effect was shown in all three brain structures. The magnitude of the effect of NMDA receptor blockade, however, was equivalent in stressed and unstressed rats, suggesting a role for glutamate in the effects of LPS on NF- $\kappa \mathrm{B}$ activity but not in the ability of stress to worsen LPS actions. This general role of glutamate and the NMDA receptor in the LPS-induced NF- $\kappa \mathrm{B}$ 

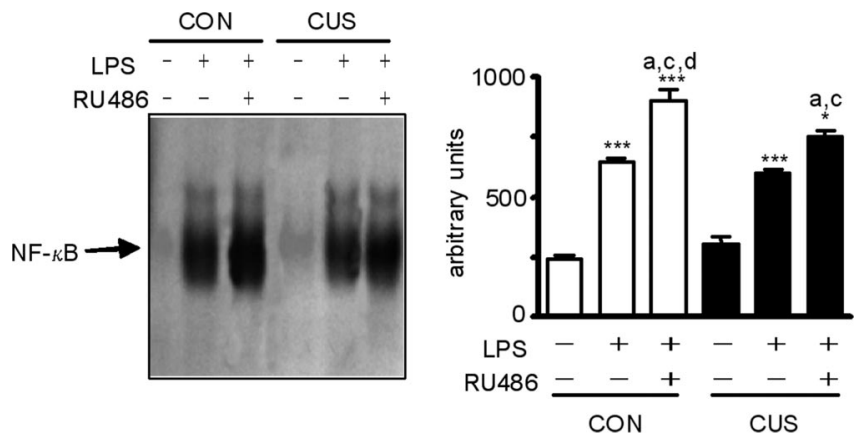

Figure 8. Influence of RU-486 on NF- $\kappa$ B activation induced by LPS in the heart of unstressed (CON) and stressed (CUS) rats. Left, Representative EMSA autoradiography. The position of $\mathrm{NF}-\kappa \mathrm{B} / \mathrm{DNA}$ binding complex is indicated. Right, Densitometric analysis of NF- $\kappa \mathrm{B} / \mathrm{DNA}$ binding complex presented in the left panel (mean $\pm \mathrm{SEM} ; n=3$ animals per group). Bonferroni's test: ${ }^{\mathrm{a}} p<0.05$ versus CON plus LPS; ${ }^{c} p<0.05$ versus CUS plus LPS; ${ }^{\mathrm{d}} p<0.05$ versus CUS plus LPS plus RU-486.

binding activation was confirmed by the combination of RU-486 and MK-801 treatment, because no further decrease in NF- $\kappa \mathrm{B}$ activation was observed, compared with RU-486 alone.

Whereas this study reveals novel proinflammatory actions of stress and GCs, both still have some of their classical antiinflammatory function. As a first example, in the frontal cortex and hippocampus of nonstressed LPS-treated rats, RU-486 increased NF- $\kappa \mathrm{B}$ binding activity, implying that in that setting, GC was anti-inflammatory. In agreement with this, in a previous report (Dinkel et al., 2003), GCs potentiated excitotoxin-induced infiltration of inflammatory cells into the hippocampus, in the absence of an excitotoxin, low physiological GC levels had antiinflammatory effects on such infiltration. Furthermore, the proinflammatory action of GCs observed in the present study was region specific, because even in the presence of LPS, GCs appeared to be anti-inflammatory in the hypothalamus and heart of stressed rats (as indicated by the RU-486 data).

Our data demonstrate an additional realm in which GCs are anti-inflammatory. Both LPS and inflammatory cytokines stimulate the hypothalamic-pituitary-adrenal axis, resulting in increased GC release (Takemura et al., 1997; Dunn et al., 1999; Hadid et al., 1999). This is thought to be a means to rein in the maximal extent of inflammation. As evidenced, when GC signaling is compromised (through hypophysectomy, surgical or chemical adrenalectomy, or GR antagonism), there is increased severity or lethality of infection (Coelho et al., 1992; Silverstein et al., 1993). In the present report, basal levels of GCs appeared to inhibit the inflammatory response under some circumstances. Specifically, in unstressed animals, RU-486 potentiated the effects of LPS in the frontal cortex and hippocampus. Moreover, treatment for $3 \mathrm{~d}$ with basal rather than stress levels of GCs decreased LPS effects in the frontal cortex and hippocampus (data not shown). Furthermore, we observed that in the frontal cortex and hippocampus of unstressed rats, when RU-486 was combined with MK-801, the reduction in LPS-induced NF- $\kappa$ B activity was less effective than in rats that only received MK-801 before LPS, implying that endogenous GCs are anti-inflammatory in this setting. Thus, GCs remain anti-inflammatory hormones, amid these unexpected domains of proinflammatory action.

The mechanisms by which GCs can be either antiinflammatory or proinflammatory in the brain are not understood. However, some hypotheses can be raised. First, there is a trend toward the proinflammatory effects being more likely in the face of highly elevated, chronic GC exposure and in brain regions most sensitive to the hormone (Abraham et al., 2000; Makino et al., 2001). The role of chronicity is important, because high-dose GCs are used therapeutically for inflammatory diseases such as arthritis, asthma, and multiple sclerosis. A small literature suggests that such GCs can have adverse effects on brain function, including cognition (for review, see Sapolsky, 2004)

In addition, GC/NF- $\kappa \mathrm{B}$ interactions are probably central to determining whether proinflammatory or anti-inflammatory effects occur. For example, whereas GCs can decrease the expression of IL-8 in lung cells, they also increase the mRNA expression of Toll-like receptor-2 (TLR2), proteins that are essential to triggering the innate immune response in response to pathogens (Hermoso et al., 2004). Furthermore, GCs regulate the TLR2 promoter through the involvement of a $3^{\prime}-\mathrm{NF}-\kappa \mathrm{B}$ site, a STAT (signal transducer and activator of transcription)-binding element, and a 3'-GC response element (Hermoso et al., 2004).

As another possibility, cell type (neuron versus glia) may be relevant to whether GC is anti-inflammatory or proinflammatory. Both neurons and glia (including both astrocytes and microglia) contain GR; the contributions of each cell type to the proinflammatory GC effects are unexplored.

Collectively, our results suggest proinflammatory functions of stress and of GCs in the brain, at the same time as the classical anti-inflammatory effects occur in a peripheral organ. This is of interest, because chronic GC therapy is broadly prescribed and the long-term effects of this for brain inflammation are poorly addressed. Thus, the clinical implications of these findings may be considerable and warrant additional exploration and understanding.

\section{References}

Abraham I, Harkany T, Horvath KM, Veenema AH, Penke B, Nyakas C, Luiten PG (2000) Chronic corticosterone administration dosedependently modulates Abeta(1-42)- and NMDA-induced neurodegeneration in rat magnocellular nucleus basalis. J Neuroendocrinol 12:486-494.

Aljada A, Ghanim H, Assian E, Mohanty P, Hamouda W, Garg R, Dandona P (1999) Increased IkappaB expression and diminished nuclear NFkappaB in human mononuclear cells following hydrocortisone injection. J Clin Endocrinol Metab 84:3386-3389.

Almawi WY, Melemedjian OK (2002) Negative regulation of nuclear factorkappaB activation and function by glucocorticoids. J Mol Endocrinol 28:69-78

Armanini MP, Hutchins C, Stein BA, Sapolsky RM (1990) Glucocorticoid endangerment of hippocampal neurons is NMDA-receptor dependent. Brain Res 532:7-12.

Baeuerle PA, Henkel T (1994) Function and activation of NF-kappa B in the immune system. Annu Rev Immunol 12:141-179.

Baldwin Jr AS (1996) The NF-kappa B and I kappa B proteins: new discoveries and insights. Annu Rev Immunol 14:649-683.

Bezzi P, Domercq M, Brambilla L, Galli R, Schols D, De Clercq E, Vescovi A, Bagetta G, Kollias G, Meldolesi J, Volterra A (2001) CXCR4-activated astrocyte glutamate release via TNFalpha: amplification by microglia triggers neurotoxicity. Nat Neurosci 4:702-710.

Bierhaus A, Wolf J, Andrassy M, Rohleder N, Humpert PM, Petrov D, Ferstl R, von Eynatten M, Wendt T, Rudofsky G, Joswig M, Morcos M, Schwaninger M, McEwen B, Kirschbaum C, Nawroth PP (2003) A mechanism converting psychosocial stress into mononuclear cell activation. Proc Natl Acad Sci USA 100:1920-1925.

Chou YC, Lin WJ, Sapolsky RM (1994) Glucocorticoids increase extracellular $[3 \mathrm{H}] \mathrm{D}$-aspartate overflow in hippocampal cultures during cyanideinduced ischemia. Brain Res 654:8-14.

Coelho MM, Souza GE, Pela IR (1992) Endotoxin-induced fever is modulated by endogenous glucocorticoids in rats. Am J Physiol 263:R423-R427.

Cullinan WE, Wolfe TJ (2000) Chronic stress regulates levels of mRNA transcripts encoding beta subunits of the GABA(A) receptor in the rat stress axis. Brain Res 887:118-124. 
Cullinan WE, Herman JP, Battaglia DF, Akil H, Watson SJ (1995) Pattern and time course of immediate early gene expression in rat brain following acute stress. Neuroscience 64:477-505.

De Bosscher K, Vanden Berghe W, Haegeman G (2000) Mechanisms of anti-inflammatory action and of immunosuppression by glucocorticoids: negative interference of activated glucocorticoid receptor with transcription factors. J Neuroimmunol 109:16-22.

Dinkel K, MacPherson A, Sapolsky RM (2003) Novel glucocorticoid effects on acute inflammation in the CNS. J Neurochem 84:705-716.

Dunn AJ, Wang J, Ando T (1999) Effects of cytokines on cerebral neurotransmission. Comparison with the effects of stress. Adv Exp Med Biol 461:117-127.

Floyd RA (1999) Neuroinflammatory processes are important in neurodegenerative diseases: an hypothesis to explain the increased formation of reactive oxygen and nitrogen species as major factors involved in neurodegenerative disease development. Free Radic Biol Med 26:1346-1355.

Ghosh S, Karin M (2002) Missing pieces in the NF-kappaB puzzle. Cell 109 [Suppl]:S81-S96.

Ghosh S, May MJ, Kopp EB (1998) NF-kappa B and Rel proteins: evolutionarily conserved mediators of immune responses. Annu Rev Immunol $16: 225-260$.

Glezer I, Munhoz CD, Kawamoto EM, Marcourakis T, Avellar MC, Scavone C (2003) MK-801 and 7-Ni attenuate the activation of brain NF-kappa B induced by LPS. Neuropharmacology 45:1120-1129.

Gonzalez-Scarano F, Baltuch G (1999) Microglia as mediators of inflammatory and degenerative diseases. Annu Rev Neurosci 22:219-240.

Guerrini L, Blasi F, Denis-Donini S (1995) Synaptic activation of NF-kappa $\mathrm{B}$ by glutamate in cerebellar granule neurons in vitro. Proc Natl Acad Sci USA 92:9077-9081.

Hadid R, Spinedi E, Chautard T, Giacomini M, Gaillard RC (1999) Role of several mediators of inflammation on the mouse hypothalamo-pituitaryadrenal axis response during acute endotoxemia. Neuroimmunomodulation 6:336-343.

Heese K, Fiebich BL, Bauer J, Otten U (1998) NF-kappaB modulates lipopolysaccharide-induced microglial nerve growth factor expression. Glia 22:401-407.

Herman JP, Adams D, Prewitt C (1995) Regulatory changes in neuroendocrine stress-integrative circuitry produced by a variable stress paradigm. Neuroendocrinology 61:180-190.

Hermoso MA, Matsuguchi T, Smoak K, Cidlowski JA (2004) Glucocorticoids and tumor necrosis factor alpha cooperatively regulate toll-like receptor 2 gene expression. Mol Cell Biol 24:4743-4756.

Joels M, Karst H, Alfarez D, Heine VM, Qin Y, van Riel E, Verkuyl M, Lucassen PJ, Krugers HJ (2004) Effects of chronic stress on structure and cell function in rat hippocampus and hypothalamus. Stress 7:221-231.

Kaltschmidt C, Kaltschmidt B, Baeuerle PA (1995) Stimulation of ionotropic glutamate receptors activates transcription factor NF-kappa B in primary neurons. Proc Natl Acad Sci USA 92:9618-9622.

Krugers HJ, Maslam S, Korf J, Joels M, Holsboer F (2000) The corticosterone synthesis inhibitor metyrapone prevents hypoxia/ischemia-induced loss of synaptic function in the rat hippocampus. Stroke 31:1162-1172.

Macpherson A, Dinkel K, Sapolsky R (2005) Glucocorticoids worsen excitotoxin-induced expression of proinflammatory cytokines in hippocampal cultures. Exp Neurol 194:376-383.

Madrigal JL, Moro MA, Lizasoain I, Lorenzo P, Castrillo A, Bosca L, Leza JC (2001a) Inducible nitric oxide synthase expression in brain cortex after acute restraint stress is regulated by nuclear factor kappaB-mediated mechanisms. J Neurochem 76:532-538.

Madrigal JL, Olivenza R, Moro MA, Lizasoain I, Lorenzo P, Rodrigo J, Leza JC (2001b) Glutathione depletion, lipid peroxidation and mitochondrial dysfunction are induced by chronic stress in rat brain. Neuropsychopharmacology 24:420-429.

Madrigal JL, Caso JR, de Cristobal J, Cardenas A, Leza JC, Lizasoain I, Lorenzo P, Moro MA (2003) Effect of subacute and chronic immobilisation stress on the outcome of permanent focal cerebral ischaemia in rats. Brain Res 979:137-145.

Makino S, Kaneda T, Nishiyama M, Asaba K, Hashimoto K (2001) Lack of decrease in hypothalamic and hippocampal glucocorticoid receptor mRNA during starvation. Neuroendocrinology 74:120-128.

McKay LI, Cidlowski JA (2000) CBP (CREB binding protein) integrates NFkappaB (nuclear factor-kappaB) and glucocorticoid receptor physical interactions and antagonism. Mol Endocrinol 14:1222-1234.

Moghaddam B, Bolinao ML, Stein-Behrens B, Sapolsky R (1994) Glucocorticoids mediate the stress-induced extracellular accumulation of glutamate. Brain Res 655:251-254.

Nishio Y, Kashiwagi A, Taki H, Shinozaki K, Maeno Y, Kojima H, Maegawa H, Haneda M, Hidaka H, Yasuda H, Horiike K, Kikkawa R (1998) Altered activities of transcription factors and their related gene expression in cardiac tissues of diabetic rats. Diabetes 47:1318-1325.

O'Connor KA, Johnson JD, Hansen MK, Wieseler Frank JL, Maksimova E, Watkins LR, Maier SF (2003) Peripheral and central proinflammatory cytokine response to a severe acute stressor. Brain Res 991:123-132.

Ortiz J, Fitzgerald LW, Lane S, Terwilliger R, Nestler EJ (1996) Biochemical adaptations in the mesolimbic dopamine system in response to repeated stress. Neuropsychopharmacology 14:443-452.

Quan N, He L, Lai W, Shen T, Herkenham M (2000) Induction of I $\kappa \mathrm{B} \alpha$ mRNA expression in the brain by glucocorticoids: a negative feedback mechanism for immune-to-brain signaling. J Neurosci 20:6473-6477.

Quan N, Avitsur R, Stark JL, He L, Shah M, Caligiuri M, Padgett DA, Marucha PT, Sheridan JF (2001) Social stress increases the susceptibility to endotoxic shock. J Neuroimmunol 115:36-45.

Rong Y, Baudry M (1996) Seizure activity results in a rapid induction of nuclear factor-kappa B in adult but not juvenile rat limbic structures. J Neurochem 67:662-668.

Salinovich O, Montelaro RC (1986) Reversible staining and peptide mapping of proteins transferred to nitrocellulose after separation by sodium dodecylsulfate-polyacrylamide gel electrophoresis. Anal Biochem $156: 341-347$.

Sapolsky R (2004) Stress and cognition. In: The cognitive neurosciences, Ed 3 (Gazzaniga M, ed), p 1031. Cambridge, MA: MIT.

Sheridan JF, Dobbs C, Jung J, Chu X, Konstantinos A, Padgett D, Glaser R (1998) Stress-induced neuroendocrine modulation of viral pathogenesis and immunity. Ann NY Acad Sci 840:803-808.

Silverstein R, Hannah P, Johnson DC (1993) Natural adrenocorticosteroids do not restore resistance to endotoxin in the adrenalectomized mouse. Circ Shock 41:162-165.

Stein-Behrens BA, Elliott EM, Miller CA, Schilling JW, Newcombe R, Sapolsky RM (1992) Glucocorticoids exacerbate kainic acid-induced extracellular accumulation of excitatory amino acids in the rat hippocampus. J Neurochem 58:1730-1735.

Takemura T, Makino S, Takao T, Asaba K, Suemaru S, Hashimoto K (1997) Hypothalamic-pituitary-adrenocortical responses to single vs. repeated endotoxin lipopolysaccharide administration in the rat. Brain Res 767:181-191.

Unlap MT, Jope RS (1997) Dexamethasone attenuates NF-kappa B DNA binding activity without inducing I kappa B levels in rat brain in vivo. Brain Res Mol Brain Res 45:83-89.

Wang YS, White TD (1999) The bacterial endotoxin lipopolysaccharide causes rapid inappropriate excitation in rat cortex. J Neurochem 72:652660 . 